\section{(O) OPEN ACCESS}

\title{
Efficacy and safety of strontium ranelate in the treatment of knee osteoarthritis: results of a double-blind, randomised placebo-controlled trial
}

\author{
Jean-Yves Reginster, ${ }^{1}$ Janusz Badurski, ${ }^{2}$ Nicholas Bellamy, ${ }^{3}$ William Bensen, ${ }^{4}$ \\ Roland Chapurlat, ${ }^{5}$ Xavier Chevalier, ${ }^{6}$ Claus Christiansen, ${ }^{7}$ Harry Genant, ${ }^{8}$ \\ Federico Navarro, ${ }^{9}$ Evgeny Nasonov, ${ }^{10}$ Philip N Sambrook, ${ }^{11}$ Timothy D Spector, ${ }^{12}$ \\ Cyrus Cooper ${ }^{13}$
}

\begin{abstract}
- Additional supplementary data are published online only. To view these files please visit the journal online (http://dx.doi. org/10.1136/annrheumdis2012-202231
\end{abstract}

For numbered affiliations see end of article.

\section{Correspondence to}

Professor Jean-Yves Reginster, Department of Public Health and Health Economics,

University of Liege, 4020 Liege, Belgium;

jyreginster@ulg.ac.be

Accepted 13 September 2012 Published Online First

1 November 2012

\section{Sinked}

- http://dx.doi.org/10.1136/ annrheumdis-2012-201710

- http://dx.doi.org/10.1136/ annrheumdis-2012-202239

- http://dx.doi.org/10.1136/ annrheumdis-2012-202453

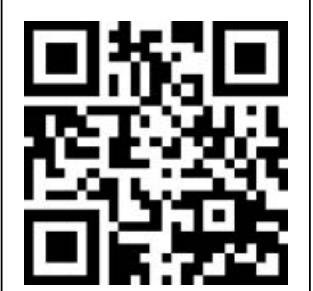

Scan to access more free content

\section{ABSTRACT}

Background Strontium ranelate is currently used for osteoporosis. The international, double-blind, randomised, placebo-controlled Strontium ranelate Efficacy in Knee Osteoarthrltis triAl evaluated its effect on radiological progression of knee osteoarthritis.

Methods Patients with knee osteoarthritis (Kellgren and Lawrence grade 2 or 3, and joint space width (JSW) $2.5-5 \mathrm{~mm}$ ) were randomly allocated to strontium ranelate $1 \mathrm{~g} /$ day $(n=558), 2 \mathrm{~g} /$ day $(n=566)$ or placebo $(n=559)$. The primary endpoint was radiographical change in JSW (medial tibiofemoral compartment) over 3 years versus placebo. Secondary endpoints included radiological progression, Western Ontario and McMaster Universities Osteoarthritis Index (WOMAC) score, and knee pain. The trial is registered (ISRCTN41323372).

Results The intention-to-treat population included 1371 patients. Treatment with strontium ranelate was associated with smaller degradations in JSW than placebo (1 g/day: -0.23 (SD 0.56) mm; 2 g/day: -0.27 (SD 0.63) mm; placebo: -0.37 (SD 0.59) mm); treatment-placebo differences were 0.14 (SE 0.04), 95\% Cl 0.05 to $0.23, p<0.001$ for $1 \mathrm{~g} /$ day and 0.10 (SE 0.04 ), $95 \% \mathrm{Cl} 0.02$ to $0.19, p=0.018$ for $2 \mathrm{~g} /$ day. Fewer radiological progressors were observed with strontium ranelate $(p<0.001$ and $p=0.012$ for 1 and $2 g /$ day). There were greater reductions in total WOMAC score $(p=0.045)$, pain subscore $(p=0.028)$, physical function subscore $(p=0.099)$ and knee pain $(p=0.065)$ with strontium ranelate $2 \mathrm{~g} /$ day. Strontium ranelate was well tolerated.

Conclusions Treatment with strontium ranelate 1 and $2 \mathrm{~g} /$ day is associated with a significant effect on structure in patients with knee osteoarthritis, and a beneficial effect on symptoms for strontium ranelate $2 \mathrm{~g} /$ day.

\section{INTRODUCTION}

Osteoarthritis is characterised by degeneration of cartilage and other structures in the joint, including subchondral bone. ${ }^{1}$ It is the most prevalent joint disease, and up to $40 \%$ of those over 65 may suffer from knee or hip osteoarthritis. ${ }^{2}$ Current management strategies focus on relieving symptoms and improving function through non-pharmacological and pharmacological approaches, and surgical procedures, including osteotomy, subchondral bone stimulation and possibly joint distraction, with the final option of joint replacement if these efforts fail. ${ }^{1}{ }^{3}$ Pharmacological approaches include analgesics, anti-inflammatory agents, intra-articular corticosteroids or hyaluronic acid, glucosamine sulphate, chondroitin sulphate or some experimental treatments, none of which are registered as structuremodifying.

Strontium ranelate is currently indicated for the management of postmenopausal osteoporosis, and may be hypothesised to act on both cartilage and subchondral bone. Preclinical in vitro studies indicate that it inhibits subchondral bone resorption ${ }^{4}$ and stimulates cartilage matrix formation in normal and osteoarthritic human chondrocytes. ${ }^{5}{ }^{6}$ Exploratory analyses suggest that 3 years' treatment with strontium ranelate attenuates radiological progression of spinal osteoarthritis and improves back pain. ${ }^{7}$ The aim of the 3-year international, double-blind, randomised, placebo-controlled trial-Strontium ranelate Efficacy in Knee OsteoarthrItis triAl (SEKOIA)described herein was to evaluate the effect of strontium ranelate on radiological and clinical progression of knee osteoarthritis.

\section{METHODS}

Study design and patients

SEKOIA was an international, multicentre, randomised, double-blind, placebo-controlled phase 3 trial in outpatients with knee osteoarthritis mainly in secondary care. This 3 -year study was performed in 98 centres in 18 countries. The selection criteria defined eligible patients as Caucasian ambulatory men and women aged $\geq 50$ years with knee osteoarthritis according to American College of Rheumatology criteria, ${ }^{8}$ with pain on at least half of the days of the previous month (intensity $\geq 40 \mathrm{~mm}$ on a $100-\mathrm{mm}$ visual analogue scale). On radiography, included patients were Kellgren and Lawrence ${ }^{9}$ grade 2 (ie, definite osteophytes and possible narrowing of joint space) or grade 3 (ie, moderate multiple osteophytes, definite narrowing of joint space and some sclerosis, and possible deformity of bone ends), and had joint space width (JSW) of 2.5 to $5 \mathrm{~mm}$ with predominant knee osteoarthritis of the medial tibiofemoral compartment. The investigator defined the target knee at selection. If both knees fulfilled the 
selection criteria, the target knee was the most painful; if both were equally painful, the target had the highest Kellgren and Lawrence grade and/or the lowest JSW; and if both had the same radiological score, the target knee was defined by the investigator's judgement. Exclusion criteria included knee prosthesis, recent intra-articular injection (notably glucocorticoids $<3$ months previously or hyaluronic acid $<6$ months previously), clinical deformities, secondary knee osteoarthritis, previous treatments acting on cartilage or bone metabolism (eg, oral or intravenous bisphosphonates <1 year previously, teriparatide or raloxifene $<7$ days prior to selection, and oral glucosamine $\geq 1500 \mathrm{mg}$ /day and chondroitin sulphate $<3$ months previously), and a medical history or a high risk of venous thromboembolism (contraindication for strontium ranelate). Further details of other inclusion and exclusion criteria, and more information on trial design, have been published elsewhere. ${ }^{10}$

The study conformed to the principles of the Declaration of Helsinki; it was approved by the ethics committee or institutional review board of every site. All patients provided written informed consent before randomisation. The trial is registered (ISRCTN41323372).

\section{Treatment allocation and masking}

At inclusion, patients were randomly allocated to three treatment groups (strontium ranelate 1 or $2 \mathrm{~g} /$ day or placebo) using a centralised interactive voice response system with balanced randomisation stratified by centre and gender (block size, 3). Patients were instructed to take one sachet daily of study treatment with water at bedtime after a 2-h fast. Patients and investigators were blinded to treatment allocation, and study treatments had identical appearance. During the study, patients were allowed physiotherapy, rehabilitation, alternative medicines and pain relief as necessary. Except for study medication, any pain medication was to be stopped at least five half-lives before a visit for symptom assessment. The investigators instructed their patients how long they had to stop pain medication prior to a visit, giving a number of days defined for each available treatment in a specific country. Treatments acting on cartilage (chondroitin, glucosamine sulphate $\geq 1500 \mathrm{mg}$ ) or bone metabolism (bisphosphonates), and glucocorticoids (oral, inhaled $>1500 \mu \mathrm{g} /$ day, or intra-articular, except in cases of medical need) were not allowed. ${ }^{10}$ The first patient visit was on 28 April 2006 and recruitment ended on 10 March 2008. The last visit was on 17 February 2011.

\section{Interventions and outcomes}

Knee radiographs were performed on both knees at selection and then annually on the target knee alone or upon withdrawal (patients treated $>6$ months), using a standardised technique described elsewhere. ${ }^{10}$ Briefly, the radiographer recorded a fixed flexion posterioanterior view (fixed angle $10^{\circ}$ ), using a SynaFlexer positioning frame (Synarc Inc, San Francisco, California, USA). ${ }^{11}$ Quality control procedures (Synarc Inc, Hamburg) included specifications related to image acquisition and collection (eg, depiction, positioning and beam angle); regular training for radiology technicians; determination of radiographical eligibility; and onsite and centralised digitisation and quality control of radiographs. ${ }^{10}$ All radiographs were measured centrally (INSERM UMR 1033, Lyon, France) by a single reader blinded to treatment allocation and patient identity. Each blinded post-baseline image was measured in comparison with the inclusion image to optimise reproducibility and sensitivity. ${ }^{12-14}$

Minimal JSW (mm) at the medial tibiofemoral compartment was measured using a standardised computer-assisted method, as described elsewhere. ${ }^{10} 15$ In short, magnification was determined (radio-opaque ruler) and a region of interest was delimited by a horizontal tangent to the inferior edges of each femoral condyle and two perpendiculars to the condylar margins. Within an area defined automatically by two parallel lines $15 \mathrm{~mm}$ apart (with one $10 \mathrm{~mm}$ from the condyle line), the observer delineated the tibial and femoral bone margins, to depict a polygon; JSW was the diameter of the smallest circle (automatically calculated) included in this polygon. Intrareader reproducibility was evaluated at yearly intervals, using 70 knee radiographs unlinked to the study; it was satisfactory (intraclass correlation coefficient for JSW >0.90). ${ }^{12}$ A second reading was performed by a single reader in another centre (Liege, Belgium), independently of the first centre, using the same method; inter-reader reproducibility was good (intraclass correlation coefficient for JSW >0.90).

Other investigations included Western Ontario and McMaster Universities Osteoarthritis Index (WOMAC) and global knee pain (visual analogue scale) at inclusion and six monthly intervals. WOMAC evaluates osteoarthritis health status and outcomes via 24 questions, ${ }^{16}$ expressed as a total score and pain, stiffness and physical function subscores. Each subscore is normalised to $100 \mathrm{~mm}$ and the total WOMAC score is the sum of the three normalised subscores, that is, maximal value is $300 \mathrm{~mm}$, with the lower scores indicating a better status. Urine samples were collected at baseline, at 3, 6 and 12 months, and at yearly intervals thereafter, for assessment of $\mathrm{C}$ telopeptide of type II procollagen (CTX-II), a biomarker for cartilage turn-over (performed by Supreme SA, Liege, Belgium, using an ELISA, Urine CartiLaps, ImmunDiagnostic System Nordic, Denmark). Compliance was evaluated by sachet counts. Safety assessment included recording of adverse events and clinical and laboratory parameters.

The primary endpoint was radiographical change in JSW from baseline to last evaluation over 3 years in treatment groups versus placebo. Secondary endpoints included radiological progression (joint space narrowing (JSN) $\geq 0.5 \mathrm{~mm}$ over 3 years); radioclinical progression (JSN $\geq 0.5 \mathrm{~mm}$, and lack of improvement in WOMAC pain ( $\leq 20 \%)$ over 3 years); WOMAC scores; global knee pain; and urinary CTX-II levels.

\section{Statistical methods}

At the time of the study design, the literature data on JSN progression were unclear, and a possible extension of the follow-up time to 3 years was planned if radiological progression was lower than expected. The initial sample size calculation estimated that 960 patients would be necessary for $>90 \%$ power, assuming an SD of 0.7 and a $40 \%$ dropout rate to detect a significant between-group difference in JSN of $0.3 \mathrm{~mm}$ at 2 years (two-sided Dunnett test, 5\% type I error). This was amended to $0.2 \mathrm{~mm}$ ( $\pm 10 \%$, ie, between 0.18 and $0.22 \mathrm{~mm}$ ) in May 2007 , following new findings of a lower progression in JSN in the placebo group than previously published, ${ }^{17}$ leading to an estimated sample size of 2127 patients. In March 2008, the Executive Committee decided to prolong the study to 3 years, in view of results of a blinded re-estimation of radiological progression (212 patients) indicating JSN of $0.06 \pm 0.42 \mathrm{~mm}$ after 1 year. The final estimated sample size was therefore 1600 patients allowing a treatment-placebo difference in JSN of $0.2 \mathrm{~mm}( \pm 10 \%)$ at 3 years with an SD of $0.5 \mathrm{~mm}$.

All efficacy analyses were conducted according to the intention-to-treat (ITT) principle. The ITT population included all randomised patients who had taken at least one dose of treatment and who had an assessable baseline and one postbaseline evaluation of JSW. 
Baseline characteristics are presented as numbers (\%) or mean \pm SD. Treatment-placebo difference in primary endpoint from baseline to last value was analysed using a general linear model with baseline, centre and gender as covariates, producing estimates and SEs of the adjusted differences, 95\% CIs (Dunnett type) and $\mathrm{p}$ values (adjusted according to Dunnett-Hsu ${ }^{18}$ ). A range of sensitivity analyses (described in online supplementary table S1) were conducted to investigate the impact of missing data on treatment effect. For secondary outcomes, treatmentplacebo differences in radiological and radioclinical progression from baseline to last value were analysed as estimates of the between-group difference (SE) with associated 95\% CI and $p$ value $\left(\chi^{2}\right.$ test). Treatment-placebo differences in WOMAC scores and global knee pain were analysed using mixed model for repeated measurements and the adjusted general linear model. Treatment effect was studied using a Mann-Whitney-Wilcoxon test for CTX-II (non-Gaussian distribution). Safety data are presented as number (\%) of events.

The two-sided type I error rate was set at $5 \%$. The results were analysed by the Biostatistics Division of the Institut de Recherches Internationales Servier, using SAS (V.9.1). The main analysis was confirmed by the Department of Public Health Epidemiology and Health Economics, University of Liege, Belgium.

\section{Role of the funding source}

The Executive Committee was responsible for the study design, interpretation of the results, and manuscript preparation; they had full access to study data. The sponsor was responsible for data management and statistical analyses. The sponsor supported the work of the Executive Committee, but made no scientific or research decisions independent of this committee.

\section{RESULTS}

Three thousand four hundred and thirty-eight patients were selected, 1683 were included and allocated to treatment (558 strontium ranelate $1 \mathrm{~g} /$ day; 566 strontium ranelate $2 \mathrm{~g}$ /day; and 559 placebo) and 974 (58\%) patients completed the study (figure 1).
The ITT population included 1371 patients (82\% of randomised patients) followed for $29.8 \pm 10.5$ months (mean $\pm S D$ ).

There were no relevant between-group differences at baseline (table 1). Mean age of the randomised patients was 62.9 \pm 7.5 years with a majority of women $(70 \%)$. Body mass index was $29.9 \pm 5.0 \mathrm{~kg} / \mathrm{m}^{2}$. The target knee JSW was $3.50 \pm 0.84 \mathrm{~mm}$ at baseline, patients were Kellgren and Lawrence grade 2 (62\%) or $3(38 \%)$ and total WOMAC score was $132.4 \pm 62.4 \mathrm{~mm}$. The mean duration of knee osteoarthritis was 76.7 \pm 77.7 months (about 6.4 years). One thousand three hundred and four $(76 \%)$ patients reported a medical history of musculoskeletal or connective tissue disorders, mainly back pain $(9 \%)$, arthralgia (8\%), osteopenia (5\%) and osteoporosis (5\%). At inclusion, 1148 (68\%) patients were taking treatment for osteoarthritis, mainly propionic acid-related treatments (18\%), acetic acid derivatives (12\%) or anilides (32\%). Only seven patients were taking glucosamine and one chondroitin sulphate. In general, 39\% of the patients were receiving analgesics, and three patients systemic corticosteroids for their osteoarthritis. There were no relevant differences in baseline characteristics between completed and withdrawn patients, between randomised and ITT populations or between ITT groups at baseline (table 1).

Mean compliance was $93.3 \pm 9.3 \%$ (ITT population). During the study, 1278 patients (76\% of the randomised set) received at least one concomitant treatment for osteoarthritis, mainly propionic acid derivatives (25\%), acetic acid derivatives (18\%) and anilides (39\%). Forty-six per cent of the patients took analgesics with an indication for osteoarthritis, 13 patients received glucosamine, three chondroitin sulphate, and two a combination of the two agents; $5 \%$ of the patients received systemic corticoids for their osteoarthritis. There was no relevant between-group difference (see online supplementary table S2).

JSN in the placebo group was $-0.37 \pm 0.59 \mathrm{~mm}$ over the study. Treatment with strontium ranelate was associated with significantly attenuated JSN versus placebo, with -0.23 $\pm 0.56 \mathrm{~mm}$ for $1 \mathrm{~g} /$ day and $-0.27 \pm 0.63 \mathrm{~mm}$ for $2 \mathrm{~g} /$ day from baseline to end (table 2). The estimate of the treatment-placebo difference was significant for both dosages $(p<0.001$ for $1 \mathrm{~g} /$ day

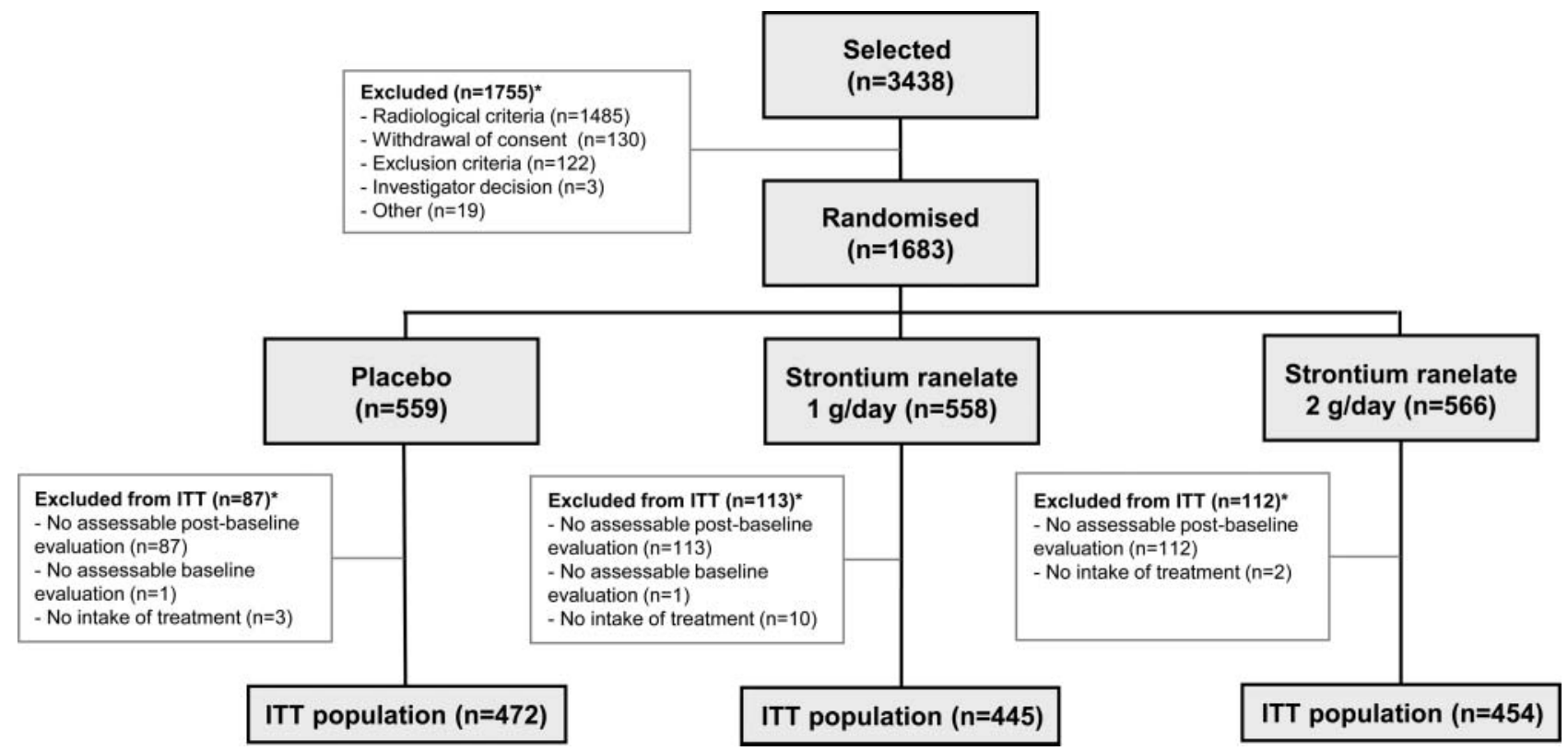

Figure 1 Trial profile. ITT, intention to treat (population). *Patients could have more than one reason. 
Table 1 Demographical and clinical characteristics at baseline in randomised patients and in the ITT population

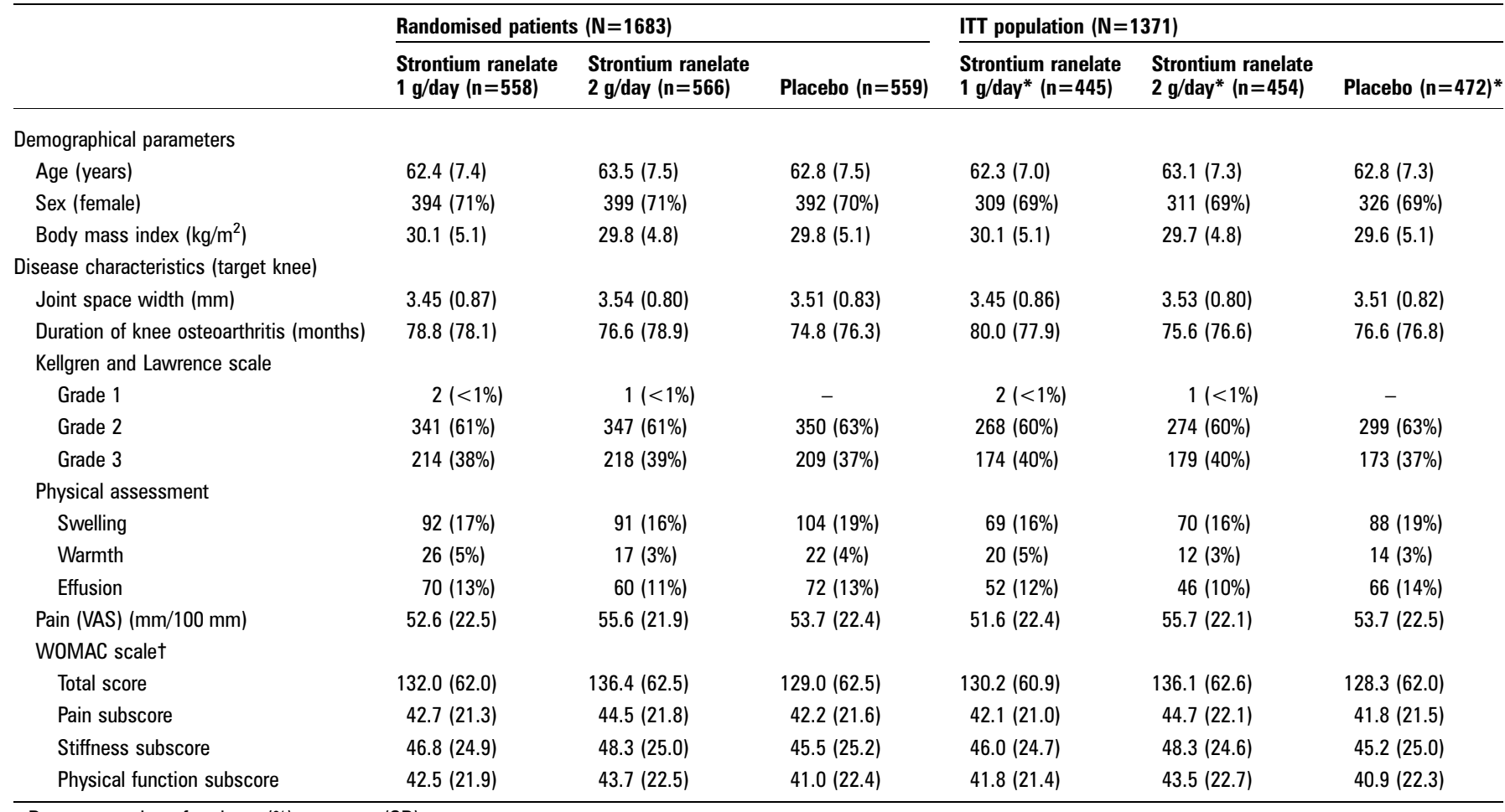

Data are number of patients (\%) or means (SD).

${ }^{*}$ No significant difference for any variable between the corresponding groups for randomised or ITT patients.

tWOMAC score is measured on a 300-mm scale; WOMAC subscores are normalised to $100 \mathrm{~mm}$.

ITT, intention-to-treat; VAS, visual analogue scale; WOMAC, Western Ontario and McMaster Universities Osteoarthritis Index.

and $\mathrm{p}=0.018$ for $2 \mathrm{~g} /$ day) (figure 2 ). Similar results were found in the second reading and a range of sensitivity analyses to assess the impact of missing data (see online supplementary table S1).
There were significantly fewer radiological and radioclinical progressors with strontium ranelate 1 and $2 \mathrm{~g}$ /day (table 2). Treatment with strontium ranelate $2 \mathrm{~g}$ /day was associated with significantly lower WOMAC total score $(p=0.045)$ and pain

Table 2 Outcomes in the intention-to-treat population $(n=1371)$

\begin{tabular}{|c|c|c|c|c|c|c|c|}
\hline & \multicolumn{3}{|c|}{ Strontium ranelate $1 \mathrm{~g} /$ day $(\mathrm{n}=445)$} & \multicolumn{3}{|c|}{ Strontium ranelate $2 \mathrm{~g} /$ day $(\mathrm{n}=454)$} & \multirow[t]{2}{*}{ Placebo $(n=472)$} \\
\hline & Value & $\begin{array}{l}\text { Difference versus } \\
\text { placebo } \\
\text { E (SE), (95\% CI) }\end{array}$ & p Value & Value & $\begin{array}{l}\text { Difference versus } \\
\text { placebo } \\
\text { E (SE), (95\% CI) }\end{array}$ & p Value & \\
\hline \multicolumn{8}{|l|}{ Primary endpoint, mean (SD) } \\
\hline Joint space width (mm) & $-0.23(0.56)$ & $\begin{array}{l}0.14(0.04) \\
(0.05 \text { to } 0.23)\end{array}$ & $<0.001$ & $-0.27(0.63)$ & $\begin{array}{l}0.10(0.04) \\
(0.02 \text { to } 0.19)\end{array}$ & 0.018 & $-0.37(0.59)$ \\
\hline \multicolumn{8}{|l|}{ Progression of disease, $\mathrm{n}(\%)$} \\
\hline Radiological progression* & $99(22 \%)$ & $\begin{array}{l}-10.80(2.9) \\
(-16.54 \text { to }-5.06)\end{array}$ & $<0.001$ & $116(26 \%)$ & $\begin{array}{l}-7.50(3.0) \\
(-13.34 \text { to }-1.66)\end{array}$ & 0.012 & $156(33 \%)$ \\
\hline Radioclinical progressiont & $32(8 \%)$ & $\begin{array}{l}-3.94(1.98) \\
(-7.83 \text { to }-0.05)\end{array}$ & 0.049 & $28(7 \%)$ & $\begin{array}{l}-5.12(1.91) \\
(-8.86 \text { to }-1.37)\end{array}$ & 0.008 & $53(12 \%)$ \\
\hline \multicolumn{8}{|l|}{ Symptoms of disease, mean (SD) $\ddagger$} \\
\hline WOMAC total score $(/ 300 \mathrm{~mm})$ & $-41.8(62.3)$ & $\begin{array}{l}-1.3(4.0) \\
(-9.0 \text { to } 6.5)\end{array}$ & 0.749 & $-51.9(66.1)$ & $\begin{array}{l}-8.0(4.0) \\
(-15.7 \text { to }-0.2)\end{array}$ & 0.045 & $-40.7(69.1)$ \\
\hline WOMAC pain subscore (/100 mm) & $-14.6(22.6)$ & $\begin{array}{l}0.1(1.3) \\
(-2.6 \text { to } 2.7)\end{array}$ & 0.969 & $-19.1(23.7)$ & $\begin{array}{l}-3.0(1.3) \\
(-5.6 \text { to }-0.3)\end{array}$ & 0.028 & $-14.7(23.5)$ \\
\hline WOMAC stiffness subscore (/100 mm) & $-15.6(26.9)$ & $\begin{array}{l}-1.0(1.6) \\
(-4.1 \text { to } 2.1)\end{array}$ & 0.523 & $-18.3(28.0)$ & $\begin{array}{l}-2.5(1.6) \\
(-5.6 \text { to } 0.6)\end{array}$ & 0.120 & $-14.0(29.4)$ \\
\hline WOMAC physical function subscore $(/ 100 \mathrm{~mm})$ & $-12.2(21.1)$ & $\begin{array}{l}-0.4(1.3) \\
(-3.0 \text { to } 2.2)\end{array}$ & 0.772 & $-15.0(22.2)$ & $\begin{array}{l}-2.2(1.3) \\
(-4.7 \text { to } 0.4)\end{array}$ & 0.099 & $-11.7(23.2)$ \\
\hline Global knee pain (VAS), (/100 mm) & $-22.9(29.0)$ & $\begin{array}{l}-0.24(1.64) \\
(-3.45 \text { to } 2.97)\end{array}$ & 0.884 & $-28.5(28.3)$ & $\begin{array}{l}-3.01(1.60) \\
(-6.20 \text { to } 0.19)\end{array}$ & 0.065 & $-24.2(29.2)$ \\
\hline
\end{tabular}

Values are number (\%) at end for progressors, mean (SD) change from baseline to end for symptoms.

* Joint space narrowing ( JSN) $\geq 0.5 \mathrm{~mm}$ over 3 years.

†JSN $\geq 0.5 \mathrm{~mm}$ and lack of improvement in WOMAC pain $(\leq 20 \%)$ pain over 3 years.

¥WOMAC score is evaluated on a $300-\mathrm{mm}$ scale; WOMAC subscores are normalised to $100 \mathrm{~mm}$, and global knee pain is reported on a $100-\mathrm{mm}$ scale.

VAS, visual analogue scale; WOMAC, Western Ontario and McMaster Universities Osteoarthritis Index. 
subscore $(p=0.028)$, and a trend toward lower physical function subscore $(p=0.099)$ and global knee pain $(p=0.065)$ (table 2, figure 2). None of these reductions was significant at $1 \mathrm{~g} /$ day. Urinary CTX-II decreased in all groups, and the between-group difference in the relative change was significant for both dosages versus placebo $(p=0.003$ for $1 \mathrm{~g} /$ day and $\mathrm{p}=0.021$ for $2 \mathrm{~g} /$ day).

The change in JSW from baseline was significantly different from placebo in both treatment groups at 12, 24 and 36 months, with no difference between the dosages at any time ( $p=0.601$ at 12 months, $p=0.149$ at 24 months and $p=0.311$ at 36 months). The reduction in total WOMAC score and pain subscore was numerically greater with treatment than placebo at every visit, with a significant between-group difference for pain subscore at 36 months ( $p=0.029$ for $2 \mathrm{~g} /$ day). The treatment-placebo difference in radiological and radioclinical progressors was significant in both treatment groups at every visit (figure 3).

Strontium ranelate was well tolerated (table 3). ${ }^{19}$ The rate of venous thromboembolic events was $<1 \%$ in all groups, and there were no cases of drug reaction with eosinophilia and systemic symptoms. There were no relevant differences in clinical or laboratory parameters, with the possible exception of creatine phosphokinase, which increased from baseline with treatment $(11.7 \pm 85.6$ and $20.7 \pm 104.4 \mathrm{IU} / \mathrm{l}$ with 1 and $2 \mathrm{~g} /$ day, respectively), but not placebo $(-0.4 \pm 68.1 \mathrm{IU} / 1)$; eight patients (three, one and four patients in the $1 \mathrm{~g} /$ day, $2 \mathrm{~g} /$ day, and placebo groups, respectively) had values greater than five times the upper limit of normal.

\section{DISCUSSION}

Our results demonstrate that strontium ranelate has structuremodifying activity in patients with knee osteoarthritis, with significantly smaller degradations in JSW over the study $(\mathrm{p}<0.001$ for $1 \mathrm{~g} /$ day and $\mathrm{p}=0.018$ for $2 \mathrm{~g} /$ day vs placebo). There were fewer patients with radiographical and radioclinical progression of osteoarthritis in the treatment groups. Additionally to this structural effect, symptomatic improvement was observed, with a significant impact on WOMAC total score and pain subscore $(p=0.045$ and $p=0.028$, respectively), and a trend towards improvement in global knee pain $(\mathrm{p}=0.065)$ at $2 \mathrm{~g} / \mathrm{day}$, but not $1 \mathrm{~g} /$ day. The safety profile of strontium ranelate was satisfactory, in line with knowledge of this agent. ${ }^{20} 21$ There was a slight mean increase in creatine phosphokinase in the treated groups as previously described for strontium ranelate. ${ }^{20}$ Pooled analysis in osteoporotic patients treated with strontium ranelate showed that increases were mainly mild, transient and reversible ${ }^{22}$; they were not associated with any clinical muscular symptoms.

These results come from a single study with a large sample size. The robustness of our observation of a structuremodifying effect for strontium ranelate is demonstrated by a range of sensitivity analyses and the rigorous methodology used for radiography acquisition and reading. ${ }^{10}$ In this context, the trial was carried out in accordance with current European and US regulatory guidelines, ${ }^{23} 24$ in terms of design and efficacy evaluation.

Osteoarthritis is not a uniform disease entity, and different phenotypes clearly exist, driven by variable changes in bone, cartilage and synovium; the links between these phenotypes are unclear. ${ }^{1}$ Strontium ranelate may exert structure-modifying effects through influences on chondrocyte and bone cell function. Evidence to support an action on cartilage via chondrocytes includes: the treatment-placebo difference in urinary
A

A Joint Space Width
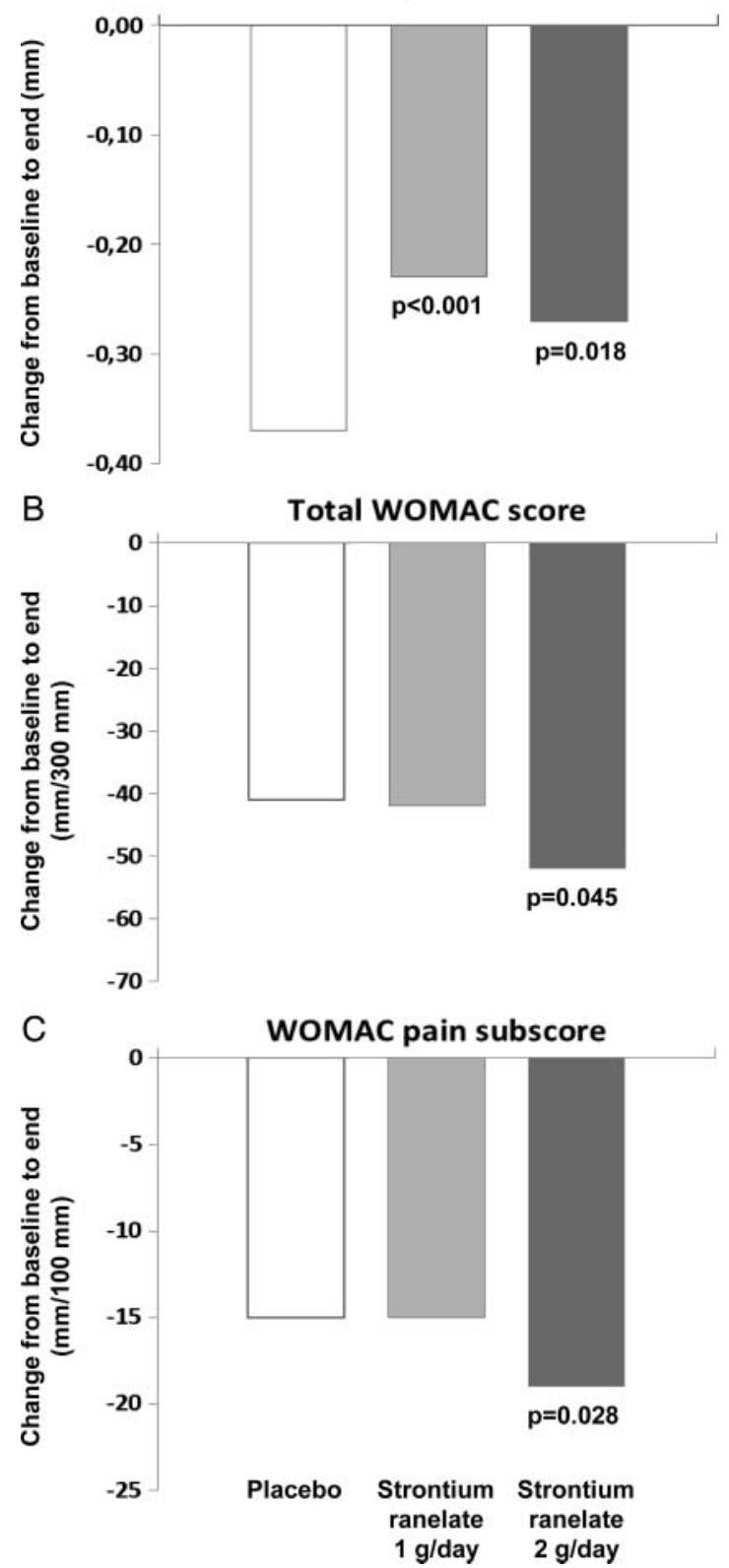

Figure 2 Effect of strontium ranelate on outcomes in knee osteoarthritis from baseline to end. (A) Change in joint space width $(\mathrm{mm})$. (B) Change in total Western Ontario and McMaster Universities Osteoarthritis Index (WOMAC) score. (C) Change in WOMAC pain subscore. $\mathrm{p}$ Values are presented versus placebo.

CTX-II in our study, which suggests lower cartilage metabolism and possibly reduced osteophyte formation; a report that strontium ranelate stimulates cartilage matrix formation in vitro, ${ }^{5}$ implying restoration of the balance between chondrocyte formation and resorption; a direct effect of strontium ranelate on proteoglycan synthesis ${ }^{5}$; and an indirect effect on insulin growth factor-1 (IGF-1). 625

Strontium ranelate is known to influence bone; however, it is unclear whether its effect on cartilage is direct or secondary to an effect on subchondral bone. Defective subchondral bone metabolism in osteoarthritis could modify chondrocytes in cartilage via local factors released during subchondral bone remodelling. ${ }^{26}$ Strontium ranelate may decrease in vitro subchondral bone resorption via the osteoprotegerin/RANK ligand pathway 


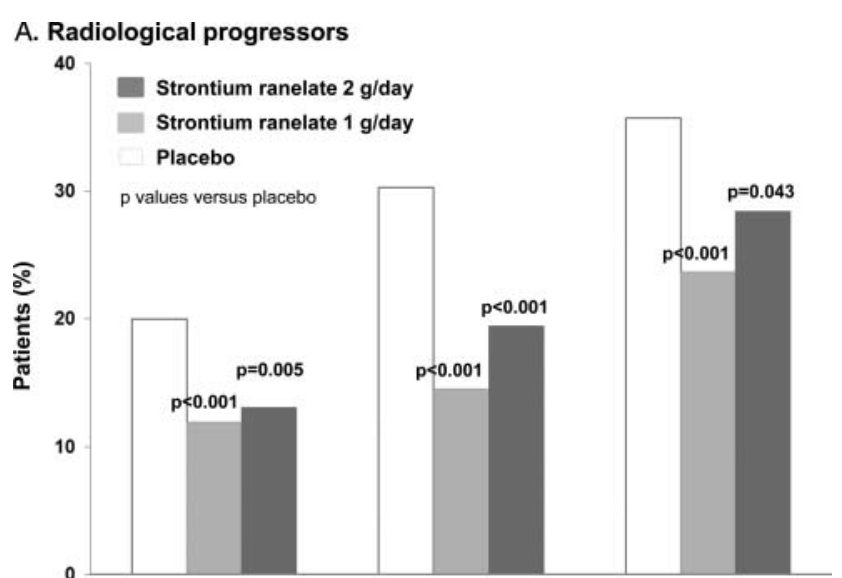

B. Radioclinical progressors

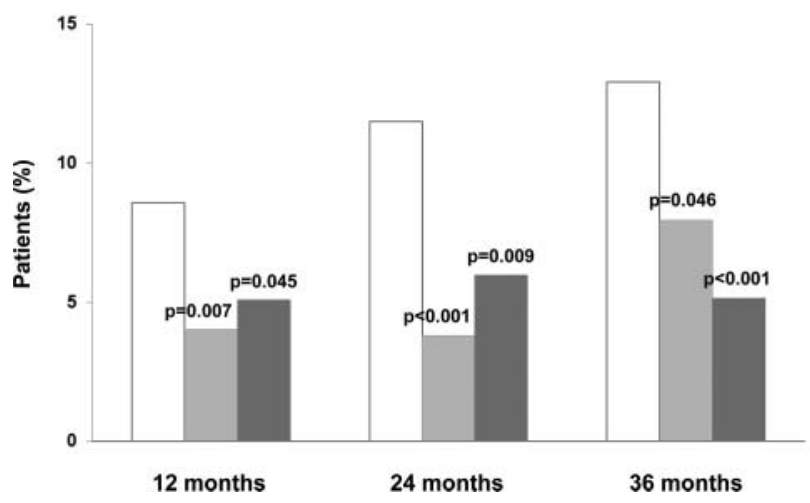

Figure 3 Impact of strontium ranelate on disease progression: percentage of patients who were radiological progressors (JSN $\geq 0.5 \mathrm{~mm}$ vs baseline, top) and radioclinical progressors (JSN $\geq 0.5 \mathrm{~mm}$ and lack of improvement in WOMAC pain ( $\leq 20 \%$ ) vs baseline, bottom) at 12,24 , and 36 months. $p$ Values are presented versus placebo.

in subchondral osteoblasts and by downregulating metalloproteases 2 and $9 .{ }^{4}$ Similar findings have been reported for strontium ranelate in osteoporotic bone. ${ }^{27} 28$ These effects on subchondral bone may directly alter the progression of osteoarthritis, or modify cartilage response to mechanical loading.

We observed differential effects of the two doses of strontium ranelate: structure appeared to be modified at both 1 and $2 \mathrm{~g} /$ day, while symptoms required $2 \mathrm{~g}$ /day for significant amelioration. This supports published evidence for different aetiological pathways in structural and symptomatic osteoarthritis. ${ }^{29}$ Osteoarthritic pain may have several causes (synovitis, osteophytes and bone marrow oedema), which are all related to inflammation or bone, rather than cartilage, which is considered to be aneural. We could hypothesise that both dosages affect the aetiological pathways leading to structure modification, but only $2 \mathrm{~g} /$ day has an additional effect on pain, possibly through its action on bone though further clinical and preclinical studies are required to explore this in more depth. In line with this, strontium ranelate has strong dose-dependent effects on bone mineral density in osteoporosis with a clinical effect at $2 \mathrm{~g} /$ day. ${ }^{30}$ Further evidence to support heterogeneity between structure and symptoms is the inconsistency noted between radiological grade and knee pain or function. ${ }^{31}{ }^{32}$ Alternative interpretations include floor and ceiling effects in pain outcome measures; and the fluctuating symptomatic natural history of osteoarthritis. ${ }^{33}$ These results raise the interesting question of whether structure modification and pain relief can both be gained by a single drug or whether a combination of drugs would be necessary in osteoarthritis

Strontium ranelate $2 \mathrm{~g} /$ day would therefore be the most appropriate dosage for clinical practice since it was associated with a $27 \%$ reduction in radiological JSN (a surrogate of cartilage loss) versus placebo. This translates into nearly a year of average radiological osteoarthritis progression saved over 3 years. Moreover, our results imply that 14 patients (95\% CI 9 to 57) would need to be treated with $2 \mathrm{~g}$ /day strontium ranelate over the study duration to prevent one case of radiological progression $\geq 0.5 \mathrm{~mm}$, a threshold known to predict osteoarthritisrelated surgery. ${ }^{34}$ Moreover, the modification of structure observed in patients with knee osteoarthritis with strontium ranelate in our study is clinically relevant, since it is accompanied by a beneficial effect on symptoms.

There are several limitations to our study. One is the difficulty of evaluating the magnitude of pain changes due to both a relatively high placebo response, which is common to all other osteoarthritis trials, ${ }^{35}$ and the difficult interpretation of changes evaluated as means as opposed to individual improvements. The dropout rate (14\% annualised; mostly for non-medical reasons (consent withdrawal)) could be regarded as a limitation; however, the annualised rate is similar to those reported for other osteoarthritis trials (11\% to $16 \%) .{ }^{17} 3336-40$ Aside from a possible role

Table 3 Emergent adverse events according to the summary of product characteristics ${ }^{19}$ and those leading to drug withdrawal

\begin{tabular}{|c|c|c|c|c|c|c|}
\hline & \multicolumn{3}{|c|}{ Patients with an event (\%) } & \multicolumn{3}{|c|}{ Patients with an event leading to treatment withdrawal (\%) } \\
\hline & $\begin{array}{l}\text { Strontium ranelate } \\
1 \mathrm{~g} / \text { day }(\mathrm{n}=548)\end{array}$ & $\begin{array}{l}\text { Strontium ranelate } \\
2 \mathrm{~g} / \text { day }(\mathrm{n}=564)\end{array}$ & Placebo $(n=556)$ & $\begin{array}{l}\text { Strontium ranelate } \\
1 \mathrm{~g} / \text { day }(\mathrm{n}=548)\end{array}$ & $\begin{array}{l}\text { Strontium ranelate } \\
2 \mathrm{~g} / \text { day }(\mathrm{n}=564)\end{array}$ & Placebo $(n=556)$ \\
\hline Diarrhoea & $32(6 \%)$ & $44(8 \%)$ & $24(4 \%)$ & $6(1 \%)$ & $9(2 \%)$ & $8(1 \%)$ \\
\hline Nausea & $19(4 \%)$ & $21(4 \%)$ & $21(4 \%)$ & $5(0.9 \%)$ & $7(1 \%)$ & $3(0.5 \%)$ \\
\hline Vomiting & $11(2 \%)$ & $9(2 \%)$ & $7(1 \%)$ & $1(0.2 \%)$ & $2(0.4 \%)$ & $3(0.5 \%)$ \\
\hline Pulmonary embolism & $2(0.4 \%)$ & $2(0.4 \%)$ & $1(0.2 \%)$ & $1(0.2 \%)$ & $1(0.2 \%)$ & $1(0.2 \%)$ \\
\hline \multicolumn{7}{|c|}{ Skin and subcutaneous disorders } \\
\hline Dermatitis & $1(0.2 \%)$ & $5(0.9 \%)$ & $1(0.2 \%)$ & - & $1(0.2 \%)$ & - \\
\hline Allergic dermatitis & $8(2 \%)$ & $6(1 \%)$ & $3(0.5 \%)$ & $2(0.4 \%)$ & $4(0.7 \%)$ & $2(0.4 \%)$ \\
\hline Eczema & $5(0.9 \%)$ & $11(2 \%)$ & $6(1 \%)$ & - & $1(0.2 \%)$ & $1(0.2 \%)$ \\
\hline
\end{tabular}

Data are number of events or number of patients (\%) in patients included in the study who had taken at least one dose of study drug. 
of the disease itself, the rate of withdrawals may be affected by study duration and the number of assessments in a relatively young population. This was anticipated in the sample size calculations, and sensitivity analyses demonstrated minimal impact of missing data. Moreover, the baseline characteristics of dropouts were similar to those of the ITT population and completers, implying that premature withdrawal did not lead to the selection of a particular subpopulation. Another limitation is the possibility of different phenotypes in osteoarthritis, ${ }^{1}$ suggesting that strontium ranelate might be more effective in certain subgroups of osteoarthritis patients, for example, those with dominant subchondral bone changes. Finally, like all studies of this type, potential causes of radiographical JSN other than cartilage thinning, such as meniscal extrusion, cannot be excluded.

In conclusion, treatment with strontium ranelate 1 and 2 g/day was associated with a significant effect on structure in patients with knee osteoarthritis. Additionally to this structure-modifying activity, there was a beneficial effect on symptoms at $2 \mathrm{~g} /$ day.

\author{
Author affiliations \\ ${ }^{1}$ Department of Public Health Epidemiology and Health Economics, University of \\ Liege, Liege, Belgium \\ ${ }^{2}$ Centre of Osteoporosis and Osteoarticular Diseases, Bialystok, Poland \\ ${ }^{3}$ Centre of National Research on Disability (CONROD), University of Queensland, \\ Herston, Queensland, Australia \\ ${ }^{4}$ DeGroot School of Medicine, McMaster University Hamilton, Hamilton, Ontario, \\ Canada \\ ${ }^{5}$ INSERM UMR 1033, Service de Rhumatologie et Pathologie Osseuse, Hôpital \\ Edouard Herriot, Université de Lyon, Lyon, France \\ ${ }^{6}$ Service de Rhumatologie, Hôpital Henri Mondor, Créteil, France \\ ${ }^{7}$ Synarc, Centre for Clinical and Basic Research (CCBR), Ballerup, Denmark \\ ${ }^{8}$ Radiology, Medicine, Epidemiology and Orthopedic Surgery, University of California, \\ San Francisco and Synarc, San Francisco, California, USA \\ ${ }^{9}$ Rheumatology Department, Hospital Universitario Virgen Macarena, Sevilla, Spain \\ ${ }^{10}$ State Institute of Rheumatology, Russian Academy of Medical Sciences, Moscow, \\ Russian Federation \\ ${ }^{11}$ Institute of Bone and Joint Research, Royal North Shore Hospital, St Leonards, \\ NSW, Australia \\ ${ }^{12}$ Department of Twin Research and Genetic Epidemiology, Kings College London, St \\ Thomas' Hospital, London, UK \\ ${ }^{13}$ MRC Lifecourse Epidemiology Unit, NIHR Musculoskeletal Biomedical Research \\ Unit, University of Southampton, University of Oxford, Oxford, UK
}

Contributors All authors participated in the design of the study, the interpretation of the data, and the writing of the article. The statistical analysis was done by the sponsor and the main analysis was independently confirmed by the Department of Public Health Epidemiology and Health Economics, University of Liege, Belgium. All authors have read and approved the final version. Study committees, coordinators and investigators are listed in an online appendix.

Funding Servier, France.

Competing interests JYR, JB, NB, WB, RC, XC, CC, HG, FN, EN, PNS, TDS and CC have received fees, research grants, or both from Servier. JYR has also received consulting fees, paid advisory boards, lecture fees, and/or grant support from Novartis, Negma, Lilly, Wyeth, Amgen, GlaxoSmithKline, Roche, Merckle, Nycomed, NPS, Theramex, UCB, Merck Sharp and Dohme, Rottapharm, IBSA, Genevrier, Teijin, Teva, Ebewee Pharma, Zodiac, Analis, Novo-Nordisk and Bristol Myers Squibb. NB is the registered copyright and trademark holder of the WOMAC Index, and the trademark and registered copyright holder of the AUSCAN index. HG has also received consulting fees or honoraria from Amgen, Novartis, Lilly, Roche, GSK, BMS, Pfizer and Merck. TDS has received fees for consulting or advisory boards from Ono Pharma, Expanscience, MSD and Amgen. CC has received consulting fees and paid advisory boards for Alliance for Better Bone Health, Glaxo Smith Kline, Roche, Merck Sharp and Dohme, Lilly, Amgen, Wyeth, Novartis and Nycomed.

Ethics approval Ethics committees or institutional review boards of every site.

Provenance and peer review Not commissioned; externally peer reviewed.

Open Access This is an Open Access article distributed in accordance with the Creative Commons Attribution Non Commercial (CC BY-NC 3.0) license, which permits others to distribute, remix, adapt, build upon this work non-commercially, and license their derivative works on different terms, provided the original work is properly cited and the use is non-commercial. See: http://creativecommons.org/licenses/by-nc/3.0/

\section{REFERENCES}

1. Bijlsma JW, Berenbaum F, Lafeber FP. Osteoarthritis: an update with relevance for clinical practice. Lancet 2011;377:2115-26.

2. Cooper C, Arden NK. Excess mortality in osteoarthritis. BMJ 2011;342:d1407.

3. Zhang W, Nuki G, Moskowitz RW, et al. OARSI recommendations for the management of hip and knee osteoarthritis: part III: changes in evidence following systematic cumulative update of research published through January 2009. Osteoarthritis Cartilage 2010;18:476-99.

4. Tat SK, Pelletier JP, Mineau F, et al. Strontium ranelate inhibits key factors affecting bone remodelling in human osteoarthritic subchondral bone osteoblasts. Bone 2011:49:559-67.

5. Henrotin Y, Labasse A, Zheng SX, et al. Strontium ranelate increases cartilage matrix formation. J Bone Miner Res 2001;16:299-308.

6. Gulhan I, Bilgili S, Gunaydin R, et al. The effect of strontium ranelate on serum insulin like growth factor-1 and leptin levels in osteoporotic post-menopausal women: a prospective study. Arch Gynecol Obstet 2008;278:437-41.

7. Bruyere 0, Delferriere D, Roux C, et al. Effects of strontium ranelate on spinal osteoarthritis progression. Ann Rheum Dis 2008;67:335-9.

8. Altman R, Asch E, Bloch D, et al. Development of criteria for the classification and reporting of osteoarthritis. Classification of osteoarthritis of the knee. Diagnostic and Therapeutic Criteria Committee of the American Rheumatism Association. Arthritis Rheum 1986;29:1039-49.

9. Kellgren MJ. The epidemiology of chronic rheumatism: atlas of standard radiographs. 2nd edn. Oxford, UK: Blackwell Scientific, 1963.

10. Cooper C, Reginster J-Y, Chapurlat R, et al. Efficacy and safety of oral strontium ranelate for the treatment of knee osteoarthritis: rationale and design of a randomised double-blind, placebo-controlled trial. Curr Med Res Opin 2012;28:231-9

11. Kothari M, Guermazi A, von Ingersleben G, et al. Fixed-flexion radiography of the knee provides reproducible joint space width measurements in osteoarthritis. Eur Radiol 2004;14:1568-73.

12. Gensburger D, Roux JP, Arlot $\mathrm{M}$, et al. Influence of blinding sequence of radiographs on the reproducibility and sensitivity to change of joint space width measurement in knee osteoarthritis. Arthritis Care Res (Hoboken) 2010;62:1699-705

13. Botha-Scheepers $\mathbf{S}$, Watt I, Breedveld FC, et al. Reading radiographs in pairs or in chronological order influences radiological progression in osteoarthritis. Rheumatology (Oxford) 2005:44:1452-5.

14. Felson DT, Nevitt MC. Blinding images to sequence in osteoarthritis: evidence from other diseases. Osteoarthritis Cartilage 2009;17:281-3.

15. Gensburger D, Arlot M, Sornay-Rendu E, et al. Radiologic assessment of age-related knee joint space changes in women: a 4-year longitudinal study. Arthritis Rheum 2009:61:336-43.

16. Bellamy N, Buchanan WW, Goldsmith $\mathrm{CH}$, et al. Validation study of WOMAC: a health status instrument for measuring clinically important patient relevant outcomes to antirheumatic drug therapy in patients with osteoarthritis of the hip or knee. J Rheumatol 1988;15:1833-40.

17. Bingham CO III, Buckland-Wright JC, Garnero P, et al. Risedronate decreases biochemical markers of cartilage degradation but does not decrease symptoms or slow radiographic progression in patients with medial compartment osteoarthritis of the knee: results of the two-year multinational knee osteoarthritis structural arthritis study. Arthritis Rheum 2006;54:3494-507.

18. Dunnett CW. A multiple comparison procedure for comparing several treatments with a control. J Am Stat Assoc 1955;50:1096-121.

19. European Medicines Agency. Strontium ranelate. Summary of product characteristics. 2009. http://www.ema.europa.eu (accessed 12 Jun 2012).

20. Meunier PJ, Roux C, Seeman E, et al. The effects of strontium ranelate on the risk of vertebral fracture in women with postmenopausal osteoporosis. N Engl J Med 2004;350:459-68.

21. Reginster JY, Seeman E, De Vernejoul MC, et al. Strontium ranelate reduces the risk of nonvertebral fractures in postmenopausal women with osteoporosis: Treatment of Peripheral Osteoporosis (TROPOS) study. J Clin Endocrinol Metab 2005;90:2816-22

22. Deeks ED, Dhillon S. Strontium ranelate: a review of its use in the treatment of postmenopausal osteoporosis. Drugs 2010;70:733-59.

23. European Medicines Agency. Guideline on clinical investigation of medicinal products used in the treatment of osteoarthritis. 2010. http://www.ema.europa.eu (accessed 12 Jun 2012).

24. Food and Drug Administration. Guidance for industry. Clinical development programs for drugs, devices, and biological products intended for the treatment of osteoarthritis. 2011. http://www.fda.gov (accessed 12 Jun 2012).

25. Montaseri A, Busch F, Mobasheri A, et al. IGF-1 and PDGF-bb suppress IL-1beta-induced cartilage degradation through down-regulation of NF-kappaB signaling: involvement of Src/PI-3K/AKT pathway. PLoS One 2011; 6:e28663.

26. Tat SK, Lajeunesse D, Pelletier JP, et al. Targeting subchondral bone for treating osteoarthritis: what is the evidence? Best Pract Res Clin Rheumatol 2010;24:51-70. 
27. Atkins GJ, Welldon KJ, Halbout $\mathrm{P}$, et al. Strontium ranelate treatment of human primary osteoblasts promotes an osteocyte-like phenotype while eliciting an osteoprotegerin response. Osteoporos Int 2009;20:653-64.

28. Caverzasio J. Strontium ranelate promotes osteoblastic cell replication through at least two different mechanisms. Bone 2008:42:1131-6.

29. Valdes AM, Spector TD. Genetic epidemiology of hip and knee osteoarthritis. Nat Rev Rheumatol 2011;7:23-32.

30. Meunier PJ, Slosman DO, Delmas PD, et al. Strontium ranelate: dose-dependent effects in established postmenopausal vertebral osteoporosis-a 2-year randomized placebo controlled trial. J Clin Endocrinol Metab 2002;87:2060-6.

31. Hannan MT, Felson DT, Pincus T. Analysis of the discordance between radiographic changes and knee pain in osteoarthritis of the knee. J Rheumatol 2000;27:1513-7.

32. Claessens AA, Schouten JS, van den Ouweland FA, et al. Do clinical findings associate with radiographic osteoarthritis of the knee? Ann Rheum Dis 1990:49:771-4.

33. Kahan A, Uebelhart D, De VF, et al. Long-term effects of chondroitins 4 and 6 sulfate on knee osteoarthritis: the study on osteoarthritis progression prevention, a two-year, randomized, double-blind, placebo-controlled trial. Arthritis Rheum 2009;60:524-33
34. Bruyere 0, Richy F, Reginster JY. Three year joint space narrowing predicts long term incidence of knee surgery in patients with osteoarthritis: an eight year prospective follow up study. Ann Rheum Dis 2005:64:1727-30.

35. Sawitzke AD, Shi H, Finco MF, et al. Clinical efficacy and safety of glucosamine chondroitin sulphate, their combination, celecoxib or placebo taken to treat osteoarthritis of the knee: 2-year results from GAIT. Ann Rheum Dis 2010;69:1459-64.

36. Pavelka K, Gatterova J, Olejarova M, et al. Glucosamine sulfate use and delay of progression of knee osteoarthritis: a 3-year, randomized, placebo-controlled, double-blind study. Arch Intern Med 2002;162:2113-23.

37. Reginster JY, Deroisy R, Rovati LC, et al. Long-term effects of glucosamine sulphate on osteoarthritis progression: a randomised, placebo-controlled clinical trial. Lancet 2001:357:251-6.

38. Sawitzke AD, Shi H, Finco MF, et al. The effect of glucosamine and/or chondroitin sulfate on the progression of knee osteoarthritis: a report from the glucosamine/chondroitin arthritis intervention trial. Arthritis Rheum 2008;58:3183-91.

39. Brandt KD, Mazzuca SA, Katz BP, et al. Effects of doxycycline on progression of osteoarthritis: results of a randomized, placebo-controlled, double-blind trial. Arthritis Rheum 2005; 52:2015-25.

40. Michel BA, Stucki G, Frey D, et al. Chondroitins 4 and 6 sulfate in osteoarthritis of the knee: a randomized, controlled trial. Arthritis Rheum 2005;52:779-86. 